\title{
El dominio forense en el Primer diccionario general etimológico de la lengua española de Roque Barcia*
}

\author{
MARÍA DO CARMO HENRÍQUEZ SALIDO
}

Universidade de Vigo

\section{INTRODUCCIÓN}

El análisis del Diccionario de Roque Bárcia, debido a la época de la historia en que se compila y a la biografía de su autor, exige, como paso previo, situarlo en el contexto político y social de la España del siglo Xix y en la historia de la lexicografía española. El contexto político y social, en el que transcurre la vida de nuestro lexicógrafo, se caracteriza por los continuos cambios de gobierno (progresistas frente a moderados) y las constantes convulsiones políticas y sociales (guerras civiles, sanciones penales y administrativas, movilizaciones de las clases medias y de amplios sectores obreros, sucesivos levantamientos progresistas, levantamientos republicanos en Andalucía, libertad de expresión y de cátedra frente a restricciones de libertades...).

En la historia de la lexicografía española su lugar está dentro de la lexicografía monolingüe no académica del último cuarto del siglo XIX, marcada por las referencias ideológicas a las circunstancias de carácter político o social, en la que domina el interés por registrar el vocabulario científico y técnico y el propósito de acoger las nuevas voces que reflejaban la situación política y social del momento. Ello no obstante, el siglo XIX va a ser testigo del monopolio académico en materia lexicográfica, por más que se publiquen diccionarios de especialidad, diccionarios enciclopédicos y diccionarios monolingües. El $D R A E$ va a influir de formas distintas «en la lexicografía española del Ochocientos, siendo la primera de todas el que esta obra constituyó un referente para ser superado a consecuencia de las fallas que presentaba para muchos desde su nacimiento» (Martínez 2000: 65). El diccionario académico es el modelo a seguir, a mejorar, a superar en el número de voces y a 'copiar', a pesar de las críticas que recibe.

* Este trabajo se inscribe en el marco del Proyecto de investigación Historia y evolución de la terminología jurídi$c a$, que se lleva a cabo en el Departamento de Lengua Española de la Universidad de Vigo, con la colaboración de Enrique de No Alonso-Misol, magistrado de la Sala de lo Social de la Audiencia Nacional. El original del Diccionario de Roque Bárcia nos lo ha cedido el abogado, Camilo Rodríguez Alonso. Nos circunscribimos al tomo III y únicamente a las letras I, J, L, M, N y O, lo cual conlleva que no aportemos cifras ni estadísticas; la extracción del material se hace a partir de la lectura de la obra. En los ejemplos del texto modernizamos la acentuación, pero en las citas respetamos los originales. Para el diccionario académico usual utilizamos la edición en DVD-ROM de la Real Academia Española (1999). Los datos sobre la biografía de Bárcia proceden de la página web del Congreso de los Diputados: http://www.congreso.es, archivo histórico (18-9-2006). 
De la vida «enredada y aviesa» de Roque Bárcia, un personaje famoso y con cierta relevancia en la política española de la segunda mitad del siglo XIX ${ }^{1}$-por el archivo histórico del Congreso sabemos que fue elegido diputado por la circunscripción de Badajoz en las elecciones del 15 de enero de 1869, por la circunscripción de Alicante en las del 8 de marzo de 1871 y por la circunscripción de Castellón en las del 10 de mayo de 1873-, conocido por sus ideales democráticos y republicanos y por sus artículos periodísticos, destacamos estos datos:

Nace en Sevilla en 1823, estudia hasta los catorce años, solo y sin maestros, hasta que pasa a cursar estudios en el Instituto San Isidro de Madrid. En 1848 está en Montpellier, en 1849 en Roma y frecuenta las bibliotecas de Francia e Italia. En 1864 aparece como redactor del periódico La Democracia, fundado por Castelar. Poco después se traslada a Cádiz y funda el periódico El Demócrata Andaluz. En 1866 tiene que emigrar a Portugal, al conocer que su casa había sido allanada por la policía, país del que regresa en 1868, al triunfar la revolución de septiembre. En 1870 es detenido por suponérsele cómplice en el asesinato de Prim, pero es puesto en libertad, porque la acusación no resultó cierta. En 1873 es uno de los dirigentes de la sublevación cantonal de Cartagena, que concluye con un rotundo fracaso, por lo cual tiene que huir a Francia. De vuelta a España, se retira de la política activa y se dedica a sus trabajos literarios y lexicográficos, como el Primer diccionario general etimológico de la lengua española, al que consagra «cinco años consecutivos de una tarea asidua, perenne y tenaz» [desde 1874 a 1879], hasta la fecha de su fallecimiento, que tiene lugar en Madrid el 3 de agosto de 1885.

Su polifacética obra la integran libros de carácter filosófico e histórico, creaciones literarias, artículos periodísticos y trabajos lexicográficos. La contribución más importante es el Primer diccionario general etimológico de la lengua española, compuesto por cinco tomos, iniciado posiblemente en torno a 1854, que el propio autor califica como el «trabajo atento, solícito, ferviente, casi apasionado, de una gran parte de mi vida, aunque haya sido con algunas interrupciones». Cuando presenta esta obra (Bárcia 1880, I: VII-LVI), en el «Prólogo» hace un ferviente elogio de Autoridades, «uno de los monumentos de nuestra lengua», cita a los más de cien autores etimologistas consultados, justifica la introducción de neologismos, para que nuestro idioma se ponga «al nivel de las naciones sabias», y señala la importancia del lenguaje técnico, ya que «cuando la ciencia ha de expresarse por la palabra, en donde no hay palabra no hay ciencia». En

1 Su infancia transcurre en la década absolutista (1823-1833), a la que seguirá la primera guerra carlista y la implantación del sistema liberal. Cuando tiene 16 años, se promulgan las primeras leyes que establecen el derecho de asociación de los trabajadores y finaliza la primera guerra carlista. En 1840 abdica la regente María Cristina y comienza la Regencia del general liberal Espartero (1841-1843). En 1843, Isabel II comienza su reinado, que se prolongará hasta 1868, año en que estalla la revolución progresista. Isabel II decide exiliarse, sin renunciar a la Corona. En septiembre de 1868 Serrano forma gobierno. En 1869 las Cortes elaboran una Constitución en la que se proclaman los derechos de los ciudadanos, la soberanía nacional y la libertad religiosa; Serrano es nombrado regente y Prim forma gobierno. En 1870 es propuesto como rey de España Amadeo de Saboya, pero mientras viaja a la Península, su único valedor, el general Prim, es asesinado en Madrid. Ante el fracaso del reinado de Amadeo I en abril de 1872, los carlistas se lanzan a una nueva guerra civil. En 1873 abdica Amadeo I, se implanta la República y por primera vez los republicanos suben al poder de la mano de Pi y Margall. En 1874 cierto descontento motiva que las Cortes obliguen a dimitir al gobierno republicano y que suba al gobierno el general Serrano. En 1875 se restaura la monarquía con Alfonso XII y se establece un sistema parlamentario liderado por el político liberal-conservador Cánovas del Castillo. En 1876 hay elecciones generales a Cortes y se promulga una nueva Constitución. En 1881 un gobierno liberal-fusionista es llamado al poder, hay libertades amplias en la cátedra y en la prensa. 
la parte destinada «A la ilustre Real Academia Española» expone sus consideraciones sobre el lenguaje humano, la historia de la lengua, su deuda con los filósofos Herder y Humboldt (de quienes proceden postulados como «el primer interés de una nación es el idioma»y «la cultura de la lengua corre pareja con la cultura de la nación») y tributa homenaje a Francisco Bopp y a su Gramática comparada, libro del que «viene una parte de mi Diccionario»; en los últimos párrafos se dirige a los Señores Académicos para darles las gracias «por las grandes honras que me habéis dispensado, al mismo tiempo que os pido perdón, porque no he sabido dar a estas horas el encanto y la utilidad que vosotros tanto merecíais y que yo hubiera deseado». Al final figura la fecha de 18 de mayo de 1879, que, en buena lógica, habría que considerar como el día en que finaliza su ingente trabajo, que se publicará en Madrid desde 1880 a 1883.

Este Diccionario apenas ha merecido el interés de los investigadores. Haensch (1997: 122) lo califica como una «obra muy defectuosa». Para Porto Dapena (2000: 119-120) es «un diccionario general de la lengua de carácter enciclopédico, en que se da cuenta de las diferentes acepciones de cada vocablo» y más que un diccionario etimológico propiamente dicho sería «un diccionario con etimologías», en el que el autor adopta «una actitud científica al tratar de encontrar, siguiendo un método comparativo, un entronque del español con otras lenguas», pero sus ideas lingüísticas «presentan una pátina de la época anterior», lo cual no ha impedido que haya sido durante mucho tiempo «el más utilizado para consultas de orden etimológico», a pesar de las «graves deficiencias y errores». García Platero (2003: 273-274) no lo considera «un repertorio etimológico tal y como lo entendemos hoy en día», sino «un diccionario enciclopédico», y destaca la documentación de voces técnicas y la «evidente subjetividad en las definiciones». De esta obra lexicográfica serían relevantes, en consecuencia, su componente enciclopédico y la falta de neutralidad del autor en el tratamiento y definiciones de las voces, hecho que no debe sorprender, ya que la vida de Bárcia no fue aséptica y es natural que no haga una descripción neutra. El carácter enciclopédico se refleja principalmente en los artículos en los que describe figuras de la historia, continentes, países, ciudades, la ciencia del derecho, la ciencia de las leyes, etc.:

Jurisprudencia. Femenino. La ciencia del derecho. II El conjunto de principios legales que tiene un pueblo o una época, en cuyo sentido se dice: LA JURISPRUDENCIA de los antiguos; la JURISPRUDENCIA romana; la JURISPRUDENCIA española. II Orden de hechos establecido por prácticas constantes, las cuales forman las tradiciones reglamentarias de una corporacion, como cuando decimos: «tales ó cuales disposiciones no se avienen con la JURISPRUDENCIA del Congreso». II Concepto propio y personalísimo con que un juez interpreta y aplica las leyes, ajustándose á lo que pudiera llamarse su criterio jurídico ó conciencia legal. Por ejemplo: sentando hipotéticamente que en la provincia de Madrid se cometen pocos estupros y muchos robos, es evidente que la audiencia territorial será más severa con los robos que con los estupros, porque así lo exige una razon moral, inseparable del espíritu de la ley, sustancia necesaria de todo derecho. Supongamos por el contrario, que en Aragon se cometen muy pocos robos y muchos estupros, y comprenderemos perfectamente que la audiencia de Zaragoza sea más severa con los estupros que con los robos, castigando con mayor grado de penalidad las acciones que necesitan mayor grado de represion. Al hablar ahora de los mencionados delitos, podremos decir que su pena es mayor ó menor, según la particular JURISPRUDENCIA de los tribunales de Madrid y de Zaragoza [...].

Legislacion. Femenino. Conjunto ó cuerpo de leyes, por las cuales se gobierna un Estado. II La ciencia de las leyes. [...]

SINONIMIA. Legislacion, jurisprudencia. La legislacion se refiere á la existencia de las leyes escritas, sean justas ó injustas, buenas ó malas. 
La jurisprudencia se refiere á los principios del derecho, á las reglas inmutables y eternas de la justicia.

La legislacion no se ocupa sino de lo que se nos manda guardar y cumplir.

La jurisprudencia establece lo que nosotros debemos dar y lo que á nosotros se debe conceder.

Lo que nosotros debemos dar, es nuestra obligacion. Lo que se nos debe conceder, es nuestro derecho.

Muchas veces se ha dicho que la legislacion de nuestro país está embrollada. No puede decirse que está embrollada nuestra jurisprudencia, porque el conocimiento prudente del derecho humano no es una cosa que admita el embrollo. [...]

Por boca de la legislacion hablan un siglo, un monarca, unas Córtes, un favorito, quizá un usurpador, tal vez un tirano, porque tiranos han sido muchos legisladores.

Por boca de la jurisprudencia habla la humanidad.

La legislacion es más extensa, más vasta: la jurisprudencia es más sabia, más justa, más moral, más religiosa.

La legislacion es un hecho: la jurisprudencia es la primera ciencia social, porque es la madre de las ciencias políticas y económicas. La economía y la política que no se funden en el conocimiento del derecho del hombre, no merecen la denominacion de ciencias.

Otra nota relevante sería la presencia de numerosos tecnicismos, y específicamente de tecnicismos jurídicos, que el autor señala con diversos indicadores no abreviados. Si en Autoridades no se puede hablar en sentido estricto de una coherencia para suministrar una determinada información sobre los usos de la palabra-entrada mediante un mismo sistema, en el Diccionario de Bárcia, conforme se puede observar desde el $D R A E$-1780 que utiliza la abreviatura for. ('forense'), aparecen varios elementos indicadores que señalan la pertenencia de la palabra al léxico común y a un campo del saber o de las actividades profesionales (así, Administración, Derecho constitucional, Forense, Jurisprudencia, Legislación...): 'administración' (incoar un expediente, libramiento), 'derecho constitucional' (iniciativa, inviolabilidad de la corona, inviolable, irresponsable), 'derecho político’ (imprescriptibilidad), 'derecho romano’ (indemnidad, indevoción, nuncupación), 'forense' (interrogatorio, intervención, legalizar...), 'jurisprudencia' (incompetente, propiedad inconmutable, notoriedad), 'legislación' (impromulgado, incompatibilidad legal), etc.

Del conjunto de fórmulas o indicaciones la que se ve con más frecuencia es la palabra Forense-aunque también hemos documentado comentarios del tipo «se usa hoy en lo forense», «adjetivo forense», «forense anticuado» o «locución latina usada en el foro» ( $c f$. los artículos correspondientes a los lemas ipso jure, licitatorio, necesario y manutener)- escrita en cursiva. Por forense Bárcia entiende 'lo perteneciente al foro', es decir, 'la plaza donde se celebraban los juicios', un sentido próximo a curia 'el ejercicio de la abogacía y la práctica de los tribunales'. Este elemento indicador de la característica relativa a este uso en particular aparece en el mismo lugar del artículo lexicográfico, cuya estructura general en la mayor parte de los artículos seleccionados es como sigue: a la cabeza va el lema escrito en letra negrita; separado por un punto y seguido está la información gramatical; a continuación, separada por un punto, aparece la marca de especialidad; siguen las acepciones correspondientes al lema, que no van numeradas, separadas por una doble barra vertical, y las «formas complejas» (DRAE-2001: XXXV), acompañadas o no de ejemplos y textualizaciones del lema escrito en mayúsculas o de disertaciones enciclopédicas:

Incompatibilidad. Femenino. La repugnancia que tiene una cosa para unirse con otra [...] II LEGAL. Legislación. Imposibilidad moral de que un funcionario desempeñe simultáneamente dos funciones, ó de que una funcion esté desempeñada al mismo tiempo por dos funcionarios. 
Incompetente. Adjetivo. Jurisprudencia. Lo que no es competente, como cuando decimos: juez INCOMPETENTE, tribunal INCOMPETENTE.

Indemnidad. Femenino. Derecho romano. La seguridad que se da á alguno de que no padecerá daño ó perjuicio.

Inviolabilidad. Femenino. La calidad que constituye inviolable alguna persona ó cosa, y así decimos: LA INVIOLABILIDAD de la ley, la INVIOLABILIDAD del magistrado [...]. II DE LA CORONA. Derecho constitucional. Alta prerrogativa que tiene el monarca, en los sistemas representativos, de no ser responsable de los actos de su gobierno. II LEGISLATIVA. La que corresponde al diputado de la nación, en cuanto á la expresión de sus ideas en el santuario de las leyes, así como á la garantía y seguridad de su persona.

Juicio. Masculino. Facultad del alma en cuya virtud el hombre puede distinguir el bien del mal y lo verdadero de lo falso [...] II DE FALTAS. Forense. Aquel en que éstas se persiguen y castigan ante los jueces de paz y con asistencia del promotor fiscal. II EXTRAORDINARIO. Forense. Aquel en que se procede sin el órden ni reglas establecidas por derecho para los JUICIOS comunes.

Lesion. Femenino. Daño ó detrimento corporal causado por alguna herida, golpe o enfermedad. [...] Forense. El daño que se causa dolosamente en las ventas por no hacerlas a su justo precio. II ENORME. Forense. El perjuicio ó agravio que alguno experimenta por haber sido engañado en algo más ó ménos de la mitad del justo precio en las compras ó ventas. II ENORMÍSIMA. Forense. El perjuicio ó agravio que alguno experimenta, por haber sido engañado en mucho más ó ménos de la mitad del justo precio en las compras y ventas.

En cuanto a la acepcion forense de lesion, tampoco puede confundirse con daño, por cuya razon fuera impropio decir: DAÑO enorme, DAÑO enormísimo, en equivalencia de LESION enorme, LESION enormísima. Esta diferencia consiste en que el daño puede ser mayor ó menor, total ó parcial, miéntras que la lesion ha de consistir precisamente en el agravio de poco ó mucho más ó ménos de la mitad en las compras y ventas.

Libramiento. Masculino. El acto y efecto de librar á otro de algun peligro. II Administración. La órden que se da por escrito para que el tesorero, mayordomo, etc., pague alguna cantidad de dinero ú otro género.

En el presente estudio nos proponemos como objetivos:

$1^{\circ}$ ) Analizar este dominio a partir exclusivamente de aquellos artículos cuyos enunciados de la definición contienen información técnica, el indicador Forense o advertencias relacionadas con este campo ${ }^{2}$, por ser el sistema utilizado por el autor para informar sobre la palabra entrada, sobre una determinada acepción o sobre su uso en particular.

2 Las voces, acepciones y formas complejas registradas, a partir de la lectura del tomo III, son las siguientes: identidad de persona, identificar, idoneidad, testigo idóneo, ignorancia de derecho, ignorancia de hecho, ilusorio, impartir, impetra, impetrable, improcedencia, improcedente, delito impune, imputabilidad, imputable, inapelable, incendiario, incidente, incitativa, incitativo, incoar un proceso, una acción, incompatible, incomunicación, incomunicado, incomunicar, indagación, indagar, indagatoriamente, indagatorio, indeclinable, indicios o sospechas vehementes, indisponible, indiviso, indotación, indubitado, infamante, infamativo, infamatorio, infame, purgar la infamia, infanticida, infanticidio, infirmación, infirmar, infligir, información, información ad perpetuam, informar, informe ${ }^{1}$, inhábil, inhabilidad, inhabilitar, inhibición, inhibido, inhibir, inhibitoriamente, inhibitorio, injuria, injuriador, injuriante, injuriar, injuriosamente, injurioso, injusticia notoria (recurso de), injusticiable, inoficioso, inquietar, inquilino, insinuación, insinuar, in sólidum, instancia, absolver de la instancia, causar instancia, primera, segunda y tercera instancia, institor, institución de heredero, instrumental, instrumento, intentar, interdicción, interdicto, interlocutoriamente, interlocutorio, interpelar, interponer, interrogatorio, interusurio, interusurio dotal, intervención, inter vivos, intestado, intimar, intimatorio, intrínseco, inventario, ipso jure, irrevocable, irritar ${ }^{2}$, írrito, iterativo, juez ad quem, juez a quo, juicio de faltas, juicio extraordinario, abrir el juicio, convenir a alguno en juicio, a juicio, parecer en juicio, pedir en juicio, juramento de calumnia, juramento decisorio, juramento judicial, 
$2^{\circ}$ ) Examinar en qué medida Bárcia, para exponer el significado o 'sentidos' de la palabra-entrada, sigue en mayor o menor grado Autoridades, para delimitar las voces y acepciones que han permanecido casi sin modificaciones (ilusorio, manutener, mora), las que han experimentado enmiendas o cambios notables en los enunciados de la definición (información, interrogatorio) o en el orden y número de acepciones (inhábil) y las que han sido suprimidas (insolutundación, sin causar instancia...), para determinar si estas transformaciones se explican porque sigue el $D R A E-1869$, que mantiene sin enmiendas notables estos artículos de Autoridades, o son fruto de una elaboración personal.

$3^{\circ}$ ) Estudiar las nuevas entradas, las palabras de nueva creación o de nueva acuñación (imputabilidad, injusticiable, interdicto...), no documentadas en Autoridades, para reseñar las que en el enunciado de la definición presentan esta marca en el DRAE-1869 (interdicto, litiscontestación, litisexpensas, mandante...) o aparecen sin ella (improcedencia, imputabilidad, litisconsorte...) y comentar las enmiendas que hace Bárcia y las que añade a las ya registradas por el DRAE-1869 (impetrable, injusticiable, notificable...).

\section{EL DOMINIO FORENSE}

Bárcia no sigue unas reglas o principios ajustados a un sistema, cuando describe y explica el vocabulario del dominio forense, y por ello no es sencillo establecer límites claros entre los ejemplos de nuestro corpus, porque la estructura de los artículos varía en función de si estamos ante una disertación enciclopédica o ante la exposición del significado de una voz o la serie de 'sentidos' con que ésta aparece en el uso de la lengua. Lo que sí parece evidente es que sigue con mayor o menor fidelidad el diccionario académico usual, pero como el DRAE tiene una historia particular es necesario tomar en consideración hechos conocidos como los que se exponen a continuación.

Antes de que se hubiese finalizado la publicación de todos los tomos del DA (17261739), los redactores ya habían observado la necesidad de introducir nuevas voces y llevar a cabo revisiones y correcciones, «defectos» que habían pretendido subsanar con la incorporación de suplementos al final de la primera edición (1780) y de la segunda (1783). En la edición tercera (1791), como hemos estudiado (Henríquez 2006), la Academia revisa las voces y acepciones del dominio forense y es patente la «censura» (p. ej., además de incluir o eliminar

juramento promisorio, juramento supletorio, jurisdicción forzosa, jurisdicción ordinaria, jurisdicción voluntaria, declinar jurisdicción, reasumir la jurisdicción, refundir o refundirse la jurisdicción, justicia ordinaria, administrar justicia, oír en justicia, pedir en justicia, justificación, justificativo, laudar, laudemio, laudo, legado, caducar el legado o fideicomiso, procedimientos legales, legalización, legalizar, legar, legatario, legítima, legitimar, lesión, lesión enorme, lesión enormísima, liberación, licitación, licitador, licitatorio, ligámen, lite, litisconsorte, litiscontestación, litisexpensas, litispendencia, locación, locación y conducción, lucro cesante, como mejor haya lugar de derecho o en derecho, no ha lugar, llamamiento, llano, mancomunar, manda, mandamiento, mandante, mandatario, mandato, manos muertas, manumisión, manumisor, manumitir, manutener, mayorazgo de agnación artificial o artificiosa, mayorazgo de agnación rigurosa, mayorazgo de masculinidad, mayorazgo regular, mayorazgo saltuario, mejorar, monitoria, mora, moratoria, muerte civil, mutuo, necesario, negativo, notificable, notificación, notificado, notificar, novación, recurso de nulidad, nulo, nuncupativo, nuncupatorio, obligación civil, obligación mixta, obligación natural, obrepción, obrepticio, obtentor, derecho de primer ocupante, ocurrencia de acreedores, oficial de la sala, oficial real, oneroso, otorgar. 
el indicador en el enunciado de la definición también realiza cambios en la lematización: así, «administrar justicia» $\mathrm{y}$ «oír en justicia» aparecen en «administrar justicia» $\mathrm{y}$ «oír en justicia»...). En las ediciones de la primera mitad del siglo XIX, la Real Academia Española sigue revisando su diccionario e introduciendo voces, acepciones y formas complejas (p. ej., juez ad quem 'el juez ante quien se interpone la apelación de otro inferior', juez a quo 'el juez de quien se apela para ante superior', en el $D R A E$-1803) o suprimiendo algunas (p. ej., insolutundación, también en el $D R A E-1803$ ), pero no hay novedades significativas, excepto en las consideraciones sobre neologismos y tecnicismos, contenidas en el prólogo de la edición novena (1843), en las que justifica las restricciones del corpus y su postura de acoger en su libro sólo los términos que habían llegado a salir «de la esfera especial a que pertenecen» y se empleaban «sin afectación en conversaciones y escritos sobre diferente materia». En resumen, transcurridos más de cien años desde la publicación del último tomo del $D A$, la nomenclatura y las definiciones de las voces del dominio forense se mantienen sin cambios de mucha entidad, porque estos términos tienden a permanecer estables.

\subsection{LAS REPRODUCCIONES LITERALES, LAS ENMIENDAS Y LAS SUPRESIONES}

Cuando Bárcia empieza su Diccionario no hay duda de que tenía delante Autoridades, que cita en bastantes páginas, y es razonable suponer que tomaría como modelo el $D R A E-1852$, pero una vez publicada la edición undécima (1869), tuvo que ser ésta la que constituyó su referente principal. Bárcia sigue esta edición -que incorpora el nuevo vocabulario político y social, aunque continúa manteniendo su desacuerdo con las propuestas de ampliar indiscriminadamente el corpus y sigue defendiendo una introducción razonada de voces técnicas-, pero no la 'copia' de manera servil, suele introducir enmiendas, aumenta el número de voces, acepciones y formas complejas, y suprime algunas. Por razones de espacio, sólo mencionaremos algunos rasgos de los tres grandes grupos que se podrían distinguir en función de los enunciados de la definición (con o sin información técnica que indica una referencia a una lengua especializada), del orden y del número de las acepciones.

En el primer grupo estarían ejemplos como ilusorio, indiviso, manutener, mora ..., cuyos enunciados de la definición e indicaciones sobre el uso son casi idénticas a las del primer diccionario académico e idénticas a las del DRAE-1869:

INDIVISO, SA. adj. Lo que no está dividido.

Pro indiviso. Term forense, que se dice de las heréncias, quando no están hechas las particiones entre los herederos (Autoridades).

Indiviso, sa. Adjetivo. Lo que no está separado ó dividido en parte. II PRO INDIVISO. Modo adverbial. Forense. Que se dice de las herencias cuando no están hechas las particiones (Bárcia). MANUTENER. v.a. Term. Forense. Mantener ò amparar alguna cosa (Autoridades).

Manutener. Activo anticuado. Mantener ó amparar. Se usa hoy en lo forense (Bárcia).

MORA. s.f. Dilacion ò tardanza. Es voz puramente Latina, y se usa mucho en la práctica forense (Autoridades).

Mora. Femenino. Forense. Dilacion o tardanza (Bárcia).

En el segundo se incluirían los ejemplos en los que se ha modificado el enunciado de la definición (información, interrogatorio...) -puede haberse reducido o ampliado la extensión 
o precisado el contenido- o se ha alterado el orden de las acepciones o suprimido o añadido alguna (inhábil, nuncupativo). Es evidente que han experimentado cambios desde Autoridades y que Bárcia hace una reproducción literal del $D R A E-1869$, pero puede introducir enmiendas como añadir una nueva acepción (p. ej., la $3^{\mathrm{a}}$ en el artículo que encabeza el lema inhábil):

INFORMACIÓN. s. f. El acto de informarse ò informar de algo.

INFORMACIÓN. Se llaman en lo forense las diligencias jurídicas que se hacen de qualquier hecho ù delito, para averiguarle, y certificarse de su verdad (Autoridades).

Informacion. Femenino. La acción y efecto de informar ó informarse. II Forense. Averiguación jurídica y legal de algun hecho ó delito. [...] II AD PERPETUAM, Ó AD PERPETUAM REI MEMORIAM. Forense. La que se hace judicialmente y á prevencion para que conste en lo sucesivo alguna cosa; como cuando los testigos son viejos ó se han de ausentar (Bárcia).

INHÁBIL. adj. de una term. Falto de las calidades y disposiciones necessárias para hacer ò recibir alguna cosa.

INHÁBIL. Se toma freqüentemente por falto de habilidad, maña ù destreza (Autoridades).

Inhábil. Adjetivo. Falto de habilidad, talento é instrucción. II El que no tiene las calidades y condiciones necesarias para hacer alguna cosa. II Forense. El que por alguna tacha ó delito no puede obtener ó servir algun cargo, empleo ó dignidad (Bárcia).

INTERROGATORIO. s. m. Term. Forense. La série de las preguntas que se hacen al reo, ò à la parte y testigos, en orden al examen del hecho ù del derecho (Autoridades).

Interrogatorio. Masculino. Forense. La serie de preguntas que se hacen al reo ó á la parte y los testigos; ó bien el conjunto de las que, para asuntos administrativos, dirigen el Gobierno ó los jefes superiores á sus subordinados (Bárcia).

NUNCUPATIVO, VA. adj. Lo que tiene el nombre de alguna cosa, sin la realidad de ella.

NUNCUPATIVO. Se llama en lo forense el testamento que no se reduce à escritura, sino solo en voz, nombrando heredero en presencia de cinco testigos (Autoridades).

Nuncupativo. Adjetivo. Forense. Se aplica al testamento que, sin reducirse á escritura, se otorga de viva voz, nombrando heredero en presencia de cinco testigos (Bárcia).

En el tercer grupo aparecerían los ejemplos en los que se eliminan las indicaciones sobre el uso o se incorpora la marca; en ambos casos el enunciado de la definición sigue siendo casi igual al de la compilación de la primera mitad del siglo XVIII e igual a la del $D R A E-1869$, aunque se halla algún caso en el que se ven nuevas formas complejas no registradas por el $D R A E$ 1869 (incompetencia material, incompetencia personal, incompetencia administrativa). Las definiciones han sido despojadas de la marca, porque con ese 'sentido' esas palabras ya se habían extendido al uso frecuente u ocasional de la lengua común:

INCOMPETENCIA. s.f. Term. forense. Falta de jurisdiccion ò autoridad en un Juez (Autoridades). Incompetencia. Femenino. Falta de competencia ó jurisdiccion. II MATERIAL. La de un juez que conoce en una materia sometida á otro juez. II PERSONAL. La de un juez que falla entre personas que no son realmente las justiciables en aquel asunto. II ADMINISTRATIVA. La imposibilidad legal en que se halla el funcionario de ejecutar actos que no están dentro de sus atribuciones (Bárcia).

INSOLVENTE. adj. de una term. Voz forense. El que no tiene para pagar las deudas que contraxo (Autoridades).

Insolvente. Adjetivo que se aplica al que no tiene con qué pagar (Bárcia).

INTERPELACIÓN. s.f. Term. Forense. Intimación ò aviso que se da à alguno para que responda (Autoridades). 
Interpelacion. Femenino. La acción y efecto de interpelar (Bárcia).

MEJORA s. f. Medra, adelantamiento y aumento de alguna cosa.

MEJORA En los Testamentos es la manda especial que el Padre hace a favor de alguno ò algunos de sus hijos, además de la legítima que les toca.

MEJORA. Se llama en la práctica forense el recurso ò apelación al Superior, fundando la queja ò agravio del auto apelado del inferior (Autoridades).

Mejora. Femenino. Medra, adelantamiento y aumento de alguna cosa. II La porcion del quinto ó del tercio ó de ambas partes, que de sus bienes dejan el padre ó la madre, el abuelo ó la abuela á alguno ó á algunos de sus hijos ó nietos, por cláusula especial en el testamento, y además de la legítima. II El recurso de apelacion al superior fundando la queja ó agravio del auto apelado del inferior (Bárcia).

Los ejemplos en los que en el enunciado de la definición se ve una indicación, no existente en Autoridades, parece que han aumentado y significaría que estas palabras con este 'sentido' estarían restringidas a los especialistas. Bárcia introduce el indicador en más enunciados e incorpora una forma compleja nueva (delito impune), pero puede no tener en cuenta el DRAE-1869 (monitorio, ria) y mantener el criterio de Autoridades (monitoria). Estas voces son verbos que denotan acciones y actuaciones llevadas a cabo en el ejercicio de la abogacía y la práctica de los tribunales [identificar, impartir, indagar, informar, inquietar, insinuar, intentar, interpelar, intimar, legitimar, notificar...]; nombres que designan cuestiones referidas a la instrucción de una causa, procedimientos y diligencias que se practican [incidente, indagación, interdicción, justificación, legalización, mandamiento, notificación, novación, obrepción...] o agentes que intervienen en una relación jurídica [legatario, mandatario]; adjetivos calificativos [impune, infame, nulo], adjetivos deverbales activos puros en -(t)ivo/-a y -(t)orio/-a (un sufijo con especial presencia en el español jurídico) y adjetivos deverbales pasivos potenciales en -ble (imputable, inapelable, incompatible, infamatorio, intimatorio, justificativo, notificable, nuncupatorio...) o adverbios en -mente (injuriosamente). Todas están en el DRAE-1869, pero sólo presentan marca en el enunciado de la definición identificar, impartir, informar, insinuar, intentar, interpelar, intimatorio, mandamiento, mandatario, notificación, notificar, nuncupatorio y obrepción:

IDENTIFICAR. v. a. Hacer una misma cosa las que son distintas (Autoridades).

Identificar. Activo. Hacer que dos ó más cosas, que en realidad son distintas, aparezcan y se consideren como una misma. Se usa más comunmente como recíproco. II Forense. Reconocer si una persona es la misma que se supone ó se busca (Bárcia).

IMPUNE. adj. de una term. Lo que se queda sin castigo, ò sale libre dél (Autoridades).

Impune. Adjetivo. Lo que queda sin castigo. II DELITO IMPUNE. Forense. Delito que no sufre la pena de la ley (Bárcia).

INFAMATORIO, RIA. adj. Lo que de hecho infáma, desacredita ù deshonra (Autoridades).

Infamatorio, ria. Adjetivo. Forense. Lo que infama (Bárcia).

MONITÓRIA. s.f. Letras ò despacho que se obtiene del Juzgado Eclesiástico, para obligar à comparecer personalmente à alguno, y deponer de lo que supiere y fuere preguntado (Autoridades).

MONITORIO, RIA. adj. Lo que sirve para avisar ó amonestar, y la persona que lo hace. II Monicion, amonestacion ó advertencia que la Iglesia ó los Obispos y Prelados dirigen á todos los fieles en general para la averiguacion de ciertos hechos que en el mismo se expresan. Alguna vez se ha usado este nombre con terminacion femenina (DRAE-1869).

Monitoria. Femenino. Forense. Despacho expedido por el tribunal eclesiástico para citar á alguno á comparecencia (Bárcia). 
NULO, LA. adj. Falto de valor y fuerza, para obligar ò tener efecto, por carecer de las solemnidades requisitas en la substancia o en el modo (Autoridades).

Nulo, la. Adjetivo. Forense. Falto de valor y fuerza para obligar ó tener efecto, por ser contrario á las leyes, ó por carecer de las solemnidades que se requieren en la sustancia ó en el modo (Bárcia).

Las formas complejas, en cuya definición se observa ahora la marca, corresponden preferentemente a «combinaciones estables de un elemento sustantivo con otras palabras que, con respecto a él, desempeñan una función adjetiva» (DRAE-2001: XXXV), en las que se da una relación entre modificado (el nombre-núcleo, que suele ser un término jurídico) y modificador (el adjetivo o un complemento con preposición) [p. ej., juramento de calumnia, juramento decisorio, juramento judicial, juramento promisorio, jurisdicción forzosa, jurisdicción ordinaria, jurisdicción voluntaria, justicia ordinaria, mayorazgo de masculinidad...]:

JURAMENTO. s. m. Afirmación, ò negación que se hace llamando à Dios por testigo de su verdad.

JURAMENTO DE CALUMNIA. Aquel con que se afianza la querella, ò acusación.

JURAMENTO JUDICIAL. Aquel que toma el Juez à pedimento de la parte, ù de oficio.

JURAMENTO PROMISSÓRIO. Aquel con que se ofrece, ò promete y testifica que se hará alguna cosa de futuro (Autoridades).

Juramento. Masculino. Afirmacion ó negación de alguna cosa poniendo por testigo á Dios, ó en sí mismo ó en sus criaturas [...] II DE CALUMNIA. Forense. El que hacen las partes al principio del pleito, testificando que no proceden ni procederán con malicia.[...] II JUDICIAL Forense. El que toma el juez de oficio ó á pedimento de la parte. II PROMISORIO. Forense. Aquel con que se promete alguna cosa [...] (Bárcia).

El número de entradas y de formas complejas suprimidas, con relación a las documentadas en Autoridades, es muy reducido; todos estos ejemplos estaban todavía en el DRAE-1791. En el DRAE-1803 se eliminan imposición de perpetuo silencio, insolutundación y sin causar instancia; en el DRAE-1817 ya no aparecen instituir heredero y mejorar la apelación:

IMPOSICIÓN de PERPETUO SILENCIO. Phrase forense con que se prohibe al actór, el que jamás vuelva à deducir la accion, ò à instar sobre ella.

INSOLUTUNDACIÓN. s.f. Voz forense. La entrega que se hace de algun efecto, con que se paga el crédito, sin obligacion de saneamiento, salga ò no fallido el efecto.

Sin causar instáncia. Phrase forense, con que se protesta, que no se quiere seguir juicio formál.

INSTITUIR HEREDERO. En lo forense, es declararle ò nombrarle, para que suceda en los derechos del difunto.

MEJORAR LA APELACIÓN. Phrase forense, que vale fundarla ante el superior, representando el agravio que se tiene en algun auto dado por el inferior, despues de haber apelado ante el.

\subsection{LAS ADICIONES}

El contexto social y político en el que vive Bárcia es la situación ideal, para que se creen numerosos neologismos y nuevos significados o 'sentidos' de las palabras, o el nuevo vocabulario del ámbito político-social, que el diccionario académico usual va introduciendo progresivamente (absolutista 'partidario del gobierno absoluto', en el DRAE-1843; liberal 'el que profesa doctrinas favorables a la libertad política de los estados', en el DRAE-1852; moderado 
'aplícase al partido liberal amante del orden y de conservar mejorando', en el DRAE-1869; progresista 'aplícase a un partido que aspira a ir mejorando o reformando progresivamente las instituciones políticas y sociales en sentido liberal; a la persona que profesa las opiniones de este partido y a lo perteneciente a él', en el $D R A E-1884$, etc.). Otras voces de nueva creación, que reflejaban la situación de la época y que nuestro lexicógrafo registra (p. ej., igualdad ante la ley 'igualdad de derechos y obligaciones, dogma del derecho político moderno' o la serie inconstitucional 'no constitucional', inconstitucionalidad 'cualidad de lo inconstitucional', inconstitucionalismo 'oposición a los preceptos constitucionales, esto es, la inconstitucionalidad elevada a sistema'...) no están en el $D R A E-1869$ y algunas no las veremos hasta el $D R A E$ 1925 (p. ej., igualdad ante la ley). Y de nuevo tenemos que poner de relieve que no siempre sigue el $D R A E-1869$, ya que puede mantener el mismo criterio de la Academia (indagatorio, interdicto, laudo, litiscontestación, litisexpensas, mancomunar, mandante, obtentor...), o, a diferencia del diccionario académico, insertar el indicador (improcedencia, imputabilidad, incomunicación, incomunicado, incomunicar, infligir, injuriante, iterativo, liberación, ligámen, litisconsorte, notificado, ocupante...), para señalar la pertenencia de la palabra a una determinada terminología:

IMPUTABILIDAD. f. La calidad que constituye imputable alguna cosa (DRAE-1869).

Imputabilidad. Femenino. Cualidad de imputable. II Forense. IMPUTABILIDAD de un hecho; responsabilidad hipotética del hecho imputable ante la ley (Bárcia).

LITISCONSORTE. com. El que litiga por la misma causa ó interés que otro, formando con él una sola parte (DRAE-1869).

Listisconsorte. Comun de dos. Forense. El que litiga por la misma causa ó interés de otro, formando con él una sola parte (Bárcia).

LITISEXPENSAS. f. pl. for. Los gastos ó costas causados, ó que se presume van á causarse, en el seguimiento de un pleito (DRAE-1869).

Litisexpensas. Femenino plural. Forense. Los gastos ó costas causados, ó que se presume van á causarse, en el seguimiento de un pleito (Bárcia).

MANDANTE. p. a. de MANDAR. El que manda. II for. La persona que en el contrato consensual llamado mandato, confía á otra la gestión ó desempeño de uno ó más negocios (DRAE-1869).

Mandante. Participio activo de mandar. El que manda. II Forense. La persona que en el contrato consensual llamado mandato, confía á otra la gestion ó desempeño de uno ó más negocios (Bárcia).

El número de entradas o formas complejas nuevas incorporadas por Bárcia, no registradas por el $D R A E-1869$, no es elevado, pero es una prueba inequívoca de su propósito de acoger en su obra el vocabulario científico y técnico (testigo idóneo, impetrable, delito impune, incoar un proceso, una acción, indagatoriamente, infirmación, inhibitoriamente, injusticiable, inter vivos, licitatorio, notificable, procedimientos legales, derecho de primer ocupante...):

Impetrable. Adjetivo. Forense. Lo que puede impetrarse ú obtenerse.

Infirmacion. Femenino. Acción ó efecto de infirmar. II Forense. Invalidacion.

Incoar. Activo. Comenzar alguna cosa. II UN EXPEDIENTE. Administracion. Principiar á instruirlo. II UN PROCESO, UNA ACCION. Forense. Entablar los procedimientos oportunos.

Legal. Adjetivo. Lo que está prescrito por Ley y es conforme á ella. [...] II PROCEDIMIENTOS LEGALES. Forense. Ritualidad marcada por la ley en la tramitacion y sustanciacion de los asuntos sometidos á la justicia.

Injusticiable. Adjetivo. Forense. No justiciable. 


\section{CONCLUSIONES PROVISIONALES}

$\left.1^{a}\right)$ Aunque esta obra apenas ha merecido el interés de los investigadores y ha sido considerada como «una obra muy defectuosa», nuestro lexicógrafo tiene el mérito de haber hecho un ingente esfuerzo para llevar a cabo una compilación en la que intenta «explicar el léxico español desde sus orígenes más remotos». En el cuerpo de la obra se encuentra interesante información sobre los niveles de uso y datos complementarios, fundamentalmente enciclopédicos, de gran interés para el dominio forense.

$\left.2^{\mathrm{a}}\right)$ Este Diccionario «no es un repertorio etimológico tal y como lo entendemos hoy en día», sino un diccionario enciclopédico, y no debe sorprender que Corominas (19551957, I: XXXIII-LIX) no lo incluya en las 'indicaciones bibliográficas'. Si bien abundan las disertaciones enciclopédicas (p. ej., jurisprudencia, legislación), éstas son escasas o poco frecuentes en el conjunto del vocabulario que integra el dominio forense.

$3^{\text {a }) ~ B a ́ r c i a ~ s i g u e ~ e l ~ D R A E-1869, ~ p e r o ~ n o ~ l o ~ h a c e ~ d e ~ m a n e r a ~ s e r v i l . ~ E n ~ n u e s t r o s ~ e j e m p l o s ~ s e ~}$ puede establecer una escala que iría desde la copia casi literal (interdicto, laudo, litisexpensas, manutener, mora...) hasta una nueva elaboración del artículo (información, inhábil), la adición de nuevas entradas (impetrable, imputabilidad, injuriante, injusticiable, licitatorio, notificable, notificado...) o de nuevas acepciones y formas complejas (testigo idóneo, incoar un proceso), la supresión (insolvente, mejora) o la inserción de la marca en el enunciado de la definición (idoneidad, imputable, inapelable, incidente, incompatible, interdicción, legitimar, notificable...), aunque lo más frecuente es que puedan coincidir varios rasgos en un mismo ejemplo. A pesar de la patente fidelidad al diccionario académico existen muchas enmiendas y notas fruto de una elaboración, y experiencia, personal en ejemplos como:

IMPUTABILIDAD. f. La calidad que constituye imputable alguna cosa (DRAE-1869).

Imputabilidad. Femenino. Cualidad de lo imputable. II Forense. IMPUTABILIDAD de un hecho; responsabilidad hipotética del hecho imputable ante la ley (Bárcia).

INCOMUNICACION. f. La accion y efecto de incomunicar ó incomunicarse (DRAE-1869).

Incomunicacion. Femenino. La accion y efecto de incomunicar ó incomunicarse. II Forense. Estado del preso á quien no se permite tratar con nadie de palabra ni por escrito (Bárcia).

\section{REFERENCIAS BIBLIOGRÁFICAS}

BARCIA, Roque (1880-1883): Primer diccionario general etimológico de la lengua española, Madrid, Establecimiento tipográfico de Álvarez Hermanos.

Corominas, Joan (1955-1957): Diccionario crítico etimológico de la lengua castellana, Madrid, Gredos.

García Platero, José Manuel (2003): «La lexicografía no académica en los siglos XVIII y XIX», en Antonia M. Medina Guerra, coord., Lexicografía española, Barcelona, Ariel, pp. 264-280.

Haensch, Günther (1997): Los diccionarios del español en el umbral del siglo XXI, Salamanca, Universidad de Salamanca. 
Henríquez SALIdo, Ma do Carmo (2006): «La calidad y censura de las voces en el DRAE-1791: la marca forense», en Mar Campos Souto y José Ignacio Pérez Pascual, eds., El diccionario de la Real Academia Española: ayer y hoy, A Coruña, Universidade da Coruña, Anexos de Revista de Lexicografia, 1, pp. 141-153.

MARTínez MARÍN, Juan (2000): «La lexicografía monolingüe del español en el siglo XIX: la corriente no académica», en Ignacio Ahumada, ed., Cinco siglos de lexicografía del español, Jaén, Universidad de Jaén, pp. 63-77.

Porto DAPENA, José-Álvaro (2000): «Diccionarios históricos y etimológicos del español», en Ignacio Ahumada, ed., Cinco siglos de lexicografía del español, Jaén, Universidad de Jaén, pp.103-125.

DA. Real ACAdemia Española (1990 [1726-1739]): Diccionario de la lengua española, Madrid, Gredos,

NTLLE. ReAl ACADEMia Española (1999): Nuevo tesoro lexicográfico de la lengua española. Madrid, Espasa-Calpe, edición en DVD. 